\title{
Electrophysiological and behavioral responses of Spodoptera littoralis caterpillars to attractive and repellent plant volatiles
}

\author{
Kacem Rharrabe ${ }^{1+}$, Emmanuelle Jacquin-Joly ${ }^{1 *}$ and Frédéric Marion-Poll ${ }^{1,2 * t}$ \\ 1 Institut National de la Recherche Agronomique, UMR iEES-Paris, Versailles cedex, France \\ ${ }^{2}$ Département Sciences de la Vie et Santé, AgroParisTech, Paris cedex, France
}

Edited by:

Stefano Colazza, University of

Palermo, Italy

\section{Reviewed by:}

Jocelyn Millar, University of

California, Riverside, USA

Peter Roessingh, University of

Amsterdam, Netherlands

\section{*Correspondence:}

Emmanuelle Jacquin-Joly, Institut

National de la Recherche

Agronomique, UMR iEES-Paris,

route de Saint Cyr, 78026 Versailles

Cedex, France

e-mail:emmanuelle.jacquin@

versailles.inra.fr;

Frédéric Marion-Poll, LEGS UPR

9034, CNRS, avenue de la Terrasse,

91198 Gif-sur-Yvette, France

e-mail: frederic.marion-pol/@

agroparistech.fr

${ }^{\dagger}$ Present address:

Kacem Rharrabe, Laboratoire

Polydisciplinaire, Faculté

Polydisciplinaire de Larache,

Université Abdelmalek Essaâdi,

Larache, Maroc:

Frédéric Marion-Poll, Laboratoire

Evolution, Génomes et Spéciation,

UPR 9034, CNRS, Gif sur Yvette,

France

\section{INTRODUCTION}

Despite their small size and rudimentary olfactory system, phytophagous caterpillars are capable of discriminating complex odors. Numerous examples show that they can actively orient toward volatiles from their host plant (Carroll and Berenbaum, 2002; Huang and Mack, 2002; Singh and Mullick, 2002; Castrejon et al., 2006; Becher and Guerin, 2009), toward plants attacked by conspecifics larvae (Carroll et al., 2006, 2008; Mooney et al., 2009), or selectively move away from odors of non-host plants (Piesik et al., 2009), and even detect conspecific adult female pheromone (Poivet et al., 2012). Several species can learn the odor of their host plant on which they feed (Saxena and Schoonhoven, 1982; Carlsson et al., 1999; Rojas and Wyatt, 1999), and perform associative learning with tastants (Salloum et al., 2011), with noxious stimuli associated with feeding on a noxious host plant (Dethier, 1980a) or with an electric shock (Blackiston et al., 2008). They have thus a very elaborate olfactory system which enables them to make ecologically relevant choices, even if the emphasis has long been placed on the adult female choice to find a proper host (Bernays and Graham, 1988; Thompson, 1988; Jallow and Zalucki, 2003), under the assumption that larvae are less mobile than adults and that "mother knows best" (Garcia-Robledo and Horvitz, 2012).

Given the variety of situations in which odors play an important role in the behavior of phytophagous larvae and given their economic importance as pest of crops, it is surprising that their olfactory system is not better described. As revealed by recent approaches (Vogt et al., 2002; Tanaka et al., 2009; Del Campo et al., 2011; Jacquin-Joly et al., 2012; Liu et al., 2012), olfactory organs express a number of olfactory-specific genes, from which only a subset are expressed in the larvae. For example, in Bombyx mori, out of 66 olfactory receptor (OR) genes identified from genome analyses, 6 are uniquely expressed in the larvae and 18 are expressed both in the larvae and the adults (Tanaka et al., 2009). In the cotton leafworm Spodoptera littoralis, 47 olfactory receptor genes have been identified, 22 of which are expressed in larval chemosensory organs (Poivet et al., 2013). However, very few attempts have been made to characterize the responses of 
larval antennal receptor neurons (Morita and Yamashita, 1961; Schoonhoven and Dethier, 1966; Dethier and Schoonhoven, 1969; Dethier, 1980b) or from maxillary palp receptor neurons in Lepidoptera (Roessingh et al., 2007).

In this work, we combined behavioral and electrophysiological approaches to ask if a correlation could be found between the attractiveness or repellent effect of odorants and the responses of olfactory cells recorded at the level of the antenna of Lepidoptera larvae. The reasoning behind this question is that if the olfactory system of the larvae is much simpler than in the adult, it may be structured differently than in the adult where multiple biologically-relevant situations tend to be detected by tuning specialized odorant receptors to salient odors (Hansson and Stensmyr, 2011). In larvae instead, given the low number of olfactory neurons present in their antennae and the simpler behavioral repertoire, we might find olfactory receptor neurons responding preferentially to attractive odorants and other responding mostly to repellent odors. In addition, we were particularly interested in analyzing the time course of the responses to repellent chemicals, which are often described as inducing a hyperpolarization, as inhibiting the spiking activity and/or as inducing a long after-response.

We studied S. littoralis Boisduval (Lepidoptera: Noctuidae) larvae first by characterizing their behavioral responses to a set of 11 odors of plant origin, chosen because they are commonly occurring in plants and because they have been reported to have either attractive or repellent effects on the behavior of insects. We then recorded the activity of olfactory neurons from their antenna in response to 5 of them which had contrasting activities in the behavioral test. By improving our understanding of the olfactory system in these larvae and by determining their orientation behavior in response to odorant stimuli, we aim at bridging the gap between the increasing number of molecular studies conducted on this insect (Malpel et al., 2008; Legeai et al., 2011; Jacquin-Joly et al., 2012; Montagne et al., 2012; Pottier et al., 2012; Poivet et al., 2013) and the scant number of physiological and behavioral studies (Poivet et al., 2012).

\section{MATERIALS AND METHODS \\ INSECTS}

S. littoralis originated from a laboratory culture maintained on semi-artificial diet (Poitout and Bues, 1974) during many generations at $24^{\circ} \mathrm{C}, 65 \pm 5 \%$ R.H., and a photoperiod of L16:D8. We used 2th and 3th instar larvae for the behavioral experiments and 5 th instar larvae for the electrophysiological experiments.

\section{CHEMICALS}

1-Hexanol, (E)-2-Hexenol, (E)-3-Hexenol, Hexanal, cis-Jasmone, Citral, Geraniol, Pentyl-Acetate, Citronellal, Camphene, and Eugenol were purchased from Sigma Aldrich (95-99\% purity). All compounds were dissolved in mineral oil (Aldrich), and diluted from $10^{-2}$ to $10^{-6} \mathrm{M}$. The solutions were kept at $4^{\circ} \mathrm{C}$ and used within 1 month.

\section{BEHAVIORAL TESTS}

We recorded the distribution over time of groups of 10 caterpillars given a choice between 2 food pellets placed into a Petri dish
( $9 \mathrm{~cm}$ diameter) (Figure 1A). Each pellet was made of $2.5 \%$ agar mixed with $0.1 \mathrm{M}$ fructose, so that caterpillars finding a pellet will start feeding on it. On the pellet, we deposited $10 \mu \mathrm{l}$ of mineral oil, either pure or with an odorant $\left(10^{-5,-4,-3,-2} \mathrm{M}\right)$. Control consisted of an experiment run with two identical pellets added with mineral oil only and put on each side of the Petri dish. Each Petri dish was placed over a white light panel and monitored during $1 \mathrm{~h}$ using a digital camera (Handycam DCR HC20E, Sony). The experiment started after 10 larvae (starved during $20 \mathrm{~h}$ prior to the experiment) were disposed in the center of the Petri dish which was covered with a lid.

A test zone and a control zone were outlined in each Petri dish (Figure 1A). The number of caterpillars in each zone was counted every $5 \mathrm{~min}$ after the beginning of the experiment to determine a preference index (PI) that was calculated from the distribution of the larvae within each zone: PI $=\left(N_{\text {test }}-N_{\text {control }}\right) /\left(N_{\text {total }}\right)$ with $N=$ number of caterpillars observed either in the control or the test zone (respectively $N_{\text {control }}$ and $N_{\text {test }}$ ). Each treatment was replicated 12 times using 10 caterpillars per Petri dish and each caterpillar was tested only once.

\section{ELECTROPHYSIOLOGICAL RECORDINGS}

Each caterpillar was restrained by wrapping its body with a strip of Parafilm ${ }^{\circledR}$ over a rigid plastic support, with only its head protruding. A thin silver electrode ( 0.015 inches dia.) was inserted into the caterpillar body up to the head, and connected to the electrical ground. Electrical signals were obtained by inserting a tungsten electrode at the base of one of the two olfactory basiconic sensilla located on the second segment of the larval antennae (sensillum B2: Laue, 2000). The electrode usually picked up the activity from up to four olfactory neurons.

The preparation was placed in front of a continuous stream $(16 \mathrm{ml} / \mathrm{s})$ of charcoal-filtered and humidified air, delivered through an empty $1 \mathrm{ml}$ plastic syring. A second glass pipette (Ringcaps $100 \mu \mathrm{l}$ ) was facing the antenna at a distance of $1 \mathrm{~cm}$ and served as a stimulus source. The stimulus was delivered by diverting an air stream $(1 \mathrm{ml} / \mathrm{s})$ into the pipette during $500 \mathrm{~ms}$, using a 3-way solenoid valve (LFAA $1200118 \mathrm{H}$, Lee Valves, USA), driven by a programmable controller (D0-05DD, Automation Direct, USA). A filter paper $(1.5 \mathrm{~cm} \times 1.5 \mathrm{~mm})$ was fitted into the stimulus pipette, and loaded with $1 \mu$ l of paraffin oil mixed with odorants (1-hexanol, citral, geraniol, pentyl-acetate or eugenol) at different dilutions $\left(10^{-6}-10^{-2} \mathrm{M}\right)$.

In each recording session, the sensillum was stimulated with one compound presented as an increasing series of concentrations $\left(10^{-6}-10^{-2} \mathrm{M}\right.$ step 10$)$. Each stimulus presentation lasted $500 \mathrm{~ms}$ and the signal activity was recorded during $3 \mathrm{~s}$, starting $1 \mathrm{~s}$ before the stimulus presentation. To prevent adaptation, the inter-stimulus interval was around $2 \mathrm{~min}$. Each stimulus was presented only once. Eight to twelve caterpillars were tested for each stimulus.

The recording electrode was connected to the probe (AI 401, Axon Instrument, USA) of an extracellular amplifier (CyberAmp 320, Axon Instrument, USA), amplified $\times 1000$ and filtered (10-2800 Hz Bessel band-pass). Data were sampled at $10 \mathrm{kHz}$ with a data acquisition card (16-bit A/D; DT9803, Data Translation, USA) under the control of a custom program 

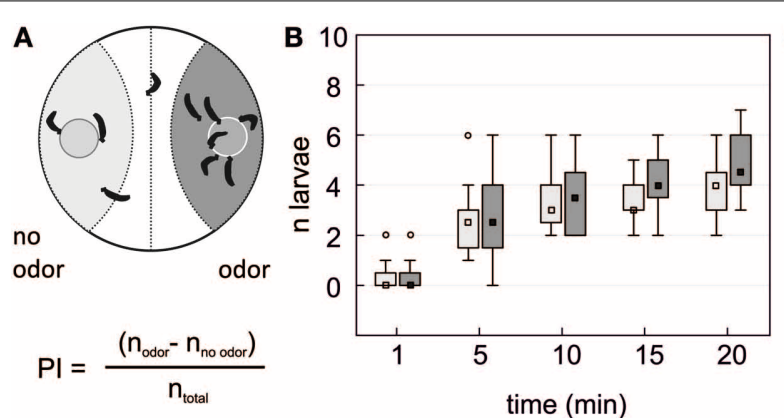

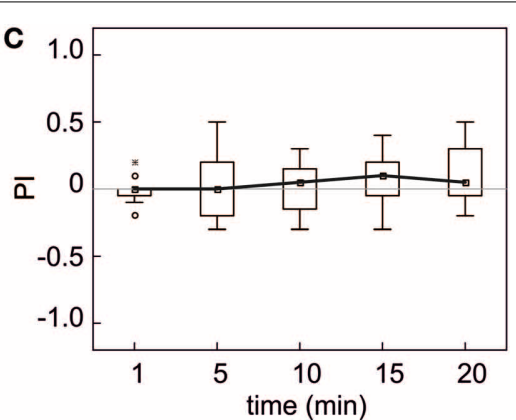

FIGURE 1 | Binary choices behavioral assay. (A) Schematic diagram of the experimental arena. Two food pellets with added odorant (odor) or with mineral oil only (no odor) are disposed in a Petri dish and 10 caterpillars are gently deposited on the midline of the bottom of the Petri dish at the beginning of the experiment. We recorded their position every five min and counted the number of larvae located within the control zone, the middle zone or the test zone. A preference index (PI) was computed to express the ratio of larvae on each side. (B) Box-and-whisker plots of the position of the larvae on each side of the arena (light gray rectangles = "no odor" side and dark gray = "odor" side) across time in the absence of any odor (control experiment) ( $n=10$ ). The boundaries of the box plots represent the first and third quartiles, and the squares represent the median value. The range of non-outlier points is indicated by the extent of a line over and below the boxes. Outliers are shown as a circle and extremes as an asterisk. In this experiment, caterpillars progressively left the central zone and approached the agar pellets. Their distribution reached a plateau after $10 \mathrm{~min}$. (C) Box-and-whisker plots of the preference index corresponding to data of (B). Raw data were transformed into a PI index, computed as the ratio of the difference between the number of larvae on each side of the arena divided by the total number of larvae. A ratio of +1 indicates complete attraction, -1 indicates complete repellency. In the absence of odor, no preference for either side was observed and the PI remained close to zero throughout the experiment. Pls are calculated after one min and then every five min for $20 \mathrm{~min}$.
dbWave (Marion-Poll, 1996). The responses were analyzed by detecting the number of action potentials during the recording period and further analyzed using Excel (Microsoft, USA). The response to each stimulus was computed as the difference between the number of spikes occurring during the stimulation minus the number of spikes recorded during $0.5 \mathrm{~s}$ before the stimulation.

\section{DATA ANALYSIS}

All statistical analyses were done with Statistica (v. 10; StatSoft Inc.). To analyse our behavioral experiments, we first determined if the data set could fit a normal distribution, using a ShapiroWilk test with a $p$-value of 0.05 . Five sets of data did not pass the test of normality. Thus, we compared multiple independent samples (groups of insects tested with different chemicals at different concentrations) with a Kruskal-Wallis ANOVA followed by multiple comparisons using concentration as an independent grouping variable. For electrophysiology, all data sets matched the Shapiro-Wilk test with a $p$-value of 0.05 . The spiking activities were thus averaged and compared to the control using a Student's $t$-test. These analyses were performed using a Bonferroni correction, with the adjusted significance level $P=0.05 / \mathrm{n}$, where $\mathrm{n}$ is the number of comparisons made within the same group. A correlation between the behavioral (PI) and electrophysiological responses (n spk/s) was made (Figure 6) by computing a regression between these parameters.

\section{RESULTS}

\section{CHEMOTAXIS BEHAVIOR ASSAY}

As caterpillars moved slowly, we noted their position every $5 \mathrm{~min}$. In the control experiment as well as for experiments involving odorants, the distribution of the caterpillars reached a plateau 1520 min after the beginning of the experiment (Figures 1B, 2). In the absence of added odor (control, mineral oil only), the larvae which found a food pellet started feeding or circled around it. In this case, the number of larvae distributed equally across the two feeding pellets and the PI was close to zero (Figures 1B,C: no odor $\left.P I_{20 \text { min }}=0.05 \pm 0.07\right)$.

In the presence of odorants, the general pattern was similar but the ratio of larvae on each side of the arena was modified; for some chemicals, this difference occurred quite rapidly, even after $5 \mathrm{~min}$. The larvae were significantly attracted by 1 hexanol, cis-jasmone, hexanal and (E)-3-hexen-1-ol at $10^{-2} \mathrm{M}$. While for 1-hexanol the choice was maintained over the observation period once established, it was not maintained for the other chemicals. A possible explanation for this phenomenon could be the occurrence of an uncontrolled gradient or air saturation after several minutes since the experiments were conducted in a closed space. For instance, the odorant gradients formed in a closed space consisting of a 96-well plate are stable for at least for $15 \mathrm{~min}$ (Louis et al., 2008). As for geraniol, although none of the experimental observations were statistically significant, the number of larvae counted on the side of the odorized pellet was consistently greater than on the non-odorized pellet side.

E-2-hexen-1-ol and citral were attractive at $10^{-3} \mathrm{M}$ but not at $10^{-2} \mathrm{M}$. Pentylacetate and citronellol did not show significant attractant or repellent effect over the range of concentrations tested. A special mention should be made for citronellol for which an unusual large variability was observed at the lowest dose $\left(10^{-5} \mathrm{M}\right)$. Lastly, camphene and especially eugenol were repellent, at $10^{-2} \mathrm{M}$.

For most chemicals, the number of larvae on each side increased regularly over the observation period. Citral appeared as a notable exception since $10^{-2} \mathrm{M}$ citral was clearly attractive after 5 and $10 \mathrm{~min}$ while the number of larvae on the odorized pellet side decreased afterwards. 


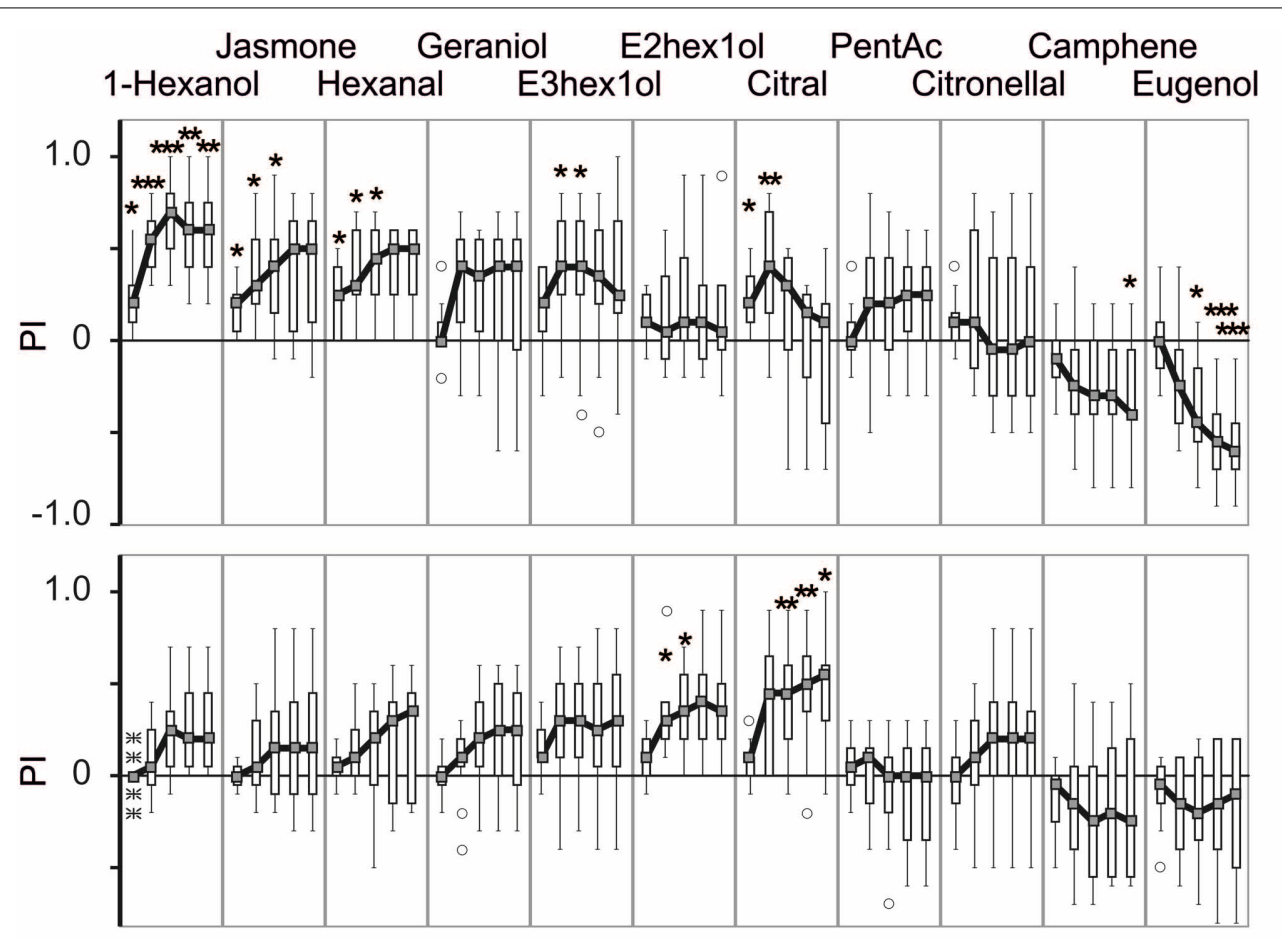

\section{$10^{-2} \mathrm{M}$}

$10^{-3} \mathrm{M}$

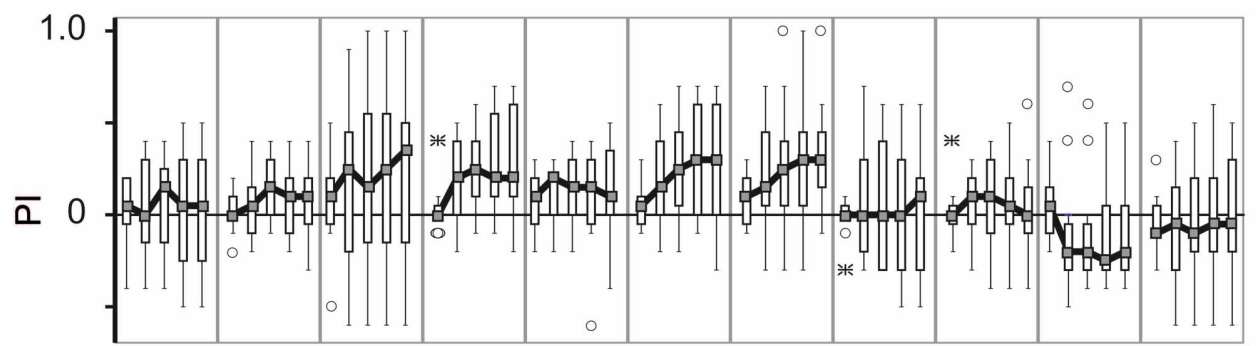

$10^{-4} \mathrm{M}$

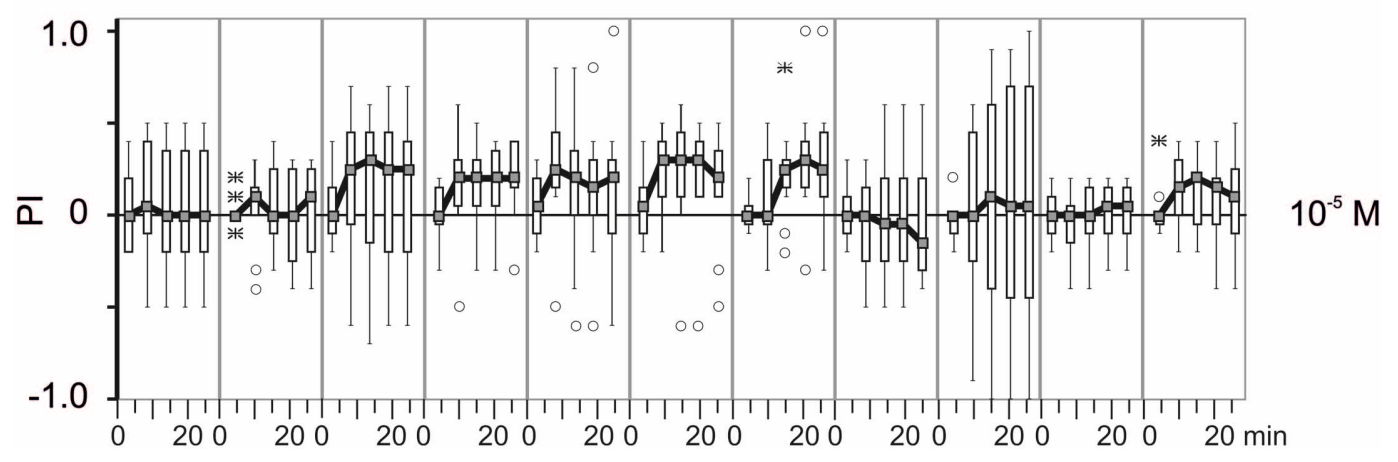

FIGURE 2 | Binary choices assay with different odorants. Box-and-whisker plots of preference indexes (PIs) observed in response of different odorants at different concentrations $\left(10^{-5}-10^{-2} \mathrm{M}\right)$ across time, using the same conventions as in Figure 1C. Each curve represents the distribution of 12 groups of 10 larvae across time (1, 5, 10, 15 and $20 \mathrm{~min})$. These observations were compared to the control (Figure 1B) using concentration as an independent grouping variable, and marked with "*" $(p<0.05)$, "**" $(p \geq 0.01)$ or " $* * *$ " $(p \geq 0.001)$.

\section{ELECTROPHYSIOLOGICAL RESPONSES}

We then asked if the behavioral effect of these chemicals as attractant or repellent could be inferred from the response induced in the olfactory neurons on the antenna of these larvae. We selected 5 molecules which differed in their behavioral effect (from attractant to repellent): 1-hexanol, geraniol, pentyl-acetate, and citral and eugenol.
All recordings reported here were obtained from sensillum B2 (Laue, 2000), by inserting a tungsten electrode at the base of it. We selected this sensillum because it was the most accessible to recording during pilot experiments. In all preparations, we obtained a high background activity which was $125.6 \pm 2.5$ spikes/s (mean \pm s.e.m.; $n=255$ recordings; time: $0-0.5 \mathrm{~s}$ ). We could usually observe $2-4$ classes of spikes 


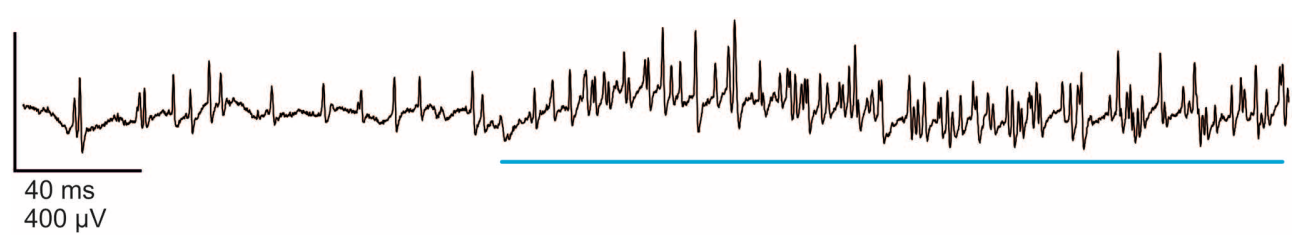

FIGURE 3 | Representative electrophysiological recording from a larval B2 olfactory sensillum. This sensillum was stimulated by 1 -hexanol (10-2 $\mathrm{M})$, showing the activity of the neurons before and during the stimulation (blue bar). Vertical bar: $400 \mu \mathrm{V}$; horizontal bar: $40 \mathrm{~ms}$.

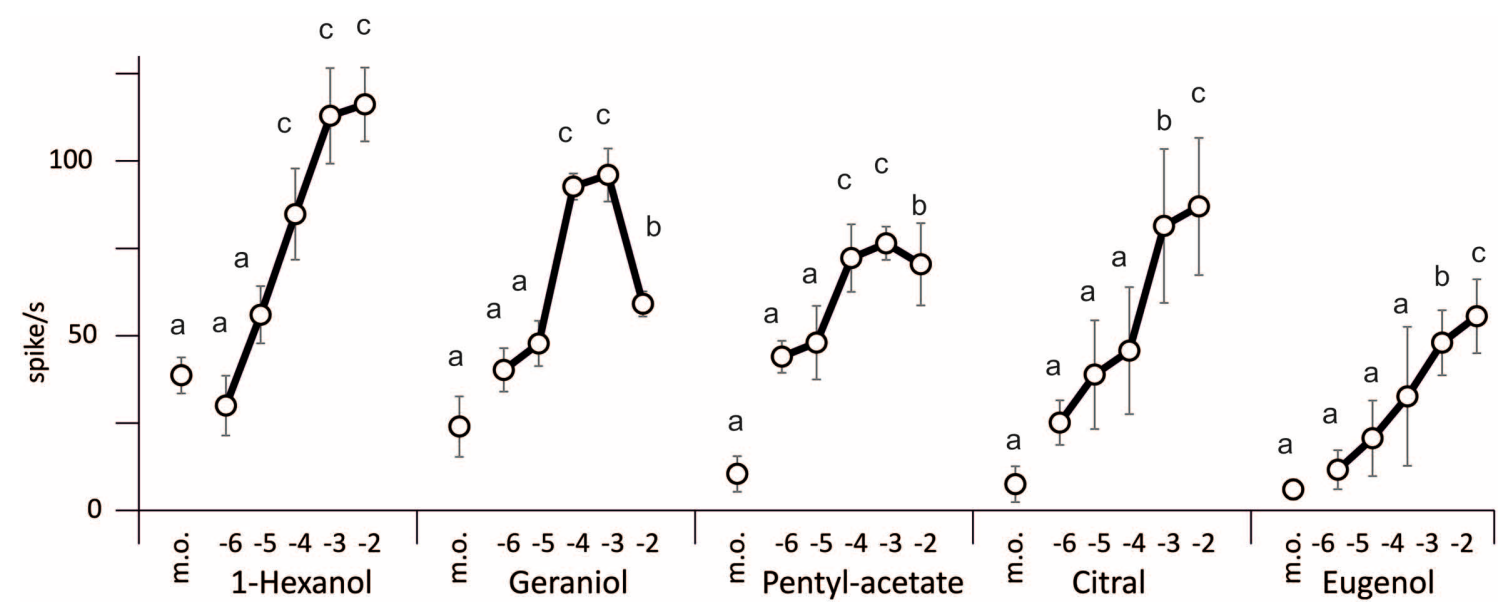

FIGURE 4 | Electrophysiological responses of the sensillum B2-5 odorants in relation to the dose. Odorants were delivered to the antenna during $500 \mathrm{~ms}$. The concentration of each odorant was expressed in $\log _{10}$ of moles (M) (m.o, mineral oil). Each data point of the graph represents the average firing rate ( \pm s.e.m.) calculated from the number of spikes emitted during the $500 \mathrm{~ms}$ stimulus minus the number of spikes elicited over the $500 \mathrm{~ms}$ period before the stimulus ( $n=8-12$ caterpillars, 1 stimulation per caterpillar). All the results were compared to the control using a Student's $t$-test with Bonferroni correction.
(Figure 3). The high level of activity in these recordings precluded performing reliable spike sorting. Therefore, the analysis we propose here is based upon the total nervous activity within one sensillum.

The response was computed as the number of action potentials during the stimulation minus the number of action potentials during the previous interval (Figure 4). The number of spikes generally increased with the concentration of the odorant stimulus, except for geraniol where the highest concentration yielded less spikes. The most stimulating compound of the series is 1-hexanol.

In order to look at the dynamic of the responses during and after the stimulation, we computed the number of spikes over consecutive $100 \mathrm{~ms}$ bins (Figure 5). A small increase of the firing was generally observed during the stimulation in response to stimulation with paraffin oil (Figure 5). The responses for the different stimuli tested were phasic, reaching a maximum within $100 \mathrm{~ms}$ after the beginning of the stimulation and then decreasing quickly, with no marked plateau during the $500 \mathrm{~ms}$ stimulus (Figure 4). The most phasic response was observed with geraniol $10^{-2} \mathrm{M}$. Following stimulation with 1-hexanol, geraniol and pentyl-acetate, we observe a marked post-stimulus inhibition. This inhibition is less prominent with citral and eugenol (Figure 5).

\section{CORRELATION BETWEEN BEHAVIOR AND ELECTROPHYSIOLOGY}

In order to compare our behavioral observations with the electrophysiological responses obtained on sensillum B2, we plotted the electrophysiological response and the behavioral response at each concentration (Figure 6). A good correlation is found for 1hexanol $\left(R^{2}=0.659\right)$ and eugenol $\left(R^{2}=0.850\right)$ but not for the other compounds with $R^{2}=0.036,0.155$, and 0.094 respectively for pentyl-acetate, geraniol and citral.

\section{DISCUSSION}

In Lepidoptera, the olfactory system has been mostly studied in the adult stage. However, the complexity of the adult olfactory system makes it difficult to understand how sensory inputs are detected at the peripheral level and translated into behaviors. By contrast, the caterpillar olfactory system is much simpler and consists of 2 olfactory organs, the antenna that bear only 3 olfactory sensilla basiconica and the maxillary palps that bear 8 sensilla, 45 of which are olfactory (Grimes and Neunzig, 1986; Laue, 2000; Vogt et al., 2002; Roessingh et al., 2007). Together, 16 olfactory neurons are found on the antennae (Schoonhoven and Dethier, 1966; Dethier and Schoonhoven, 1969). In S. littoralis, the larvae express 22 out of 47 identified olfactory receptors; 15 of them are expressed in both the antennae and the palps, 1 is expressed only in the palps and 6 are expressed only in the antennae (Poivet 

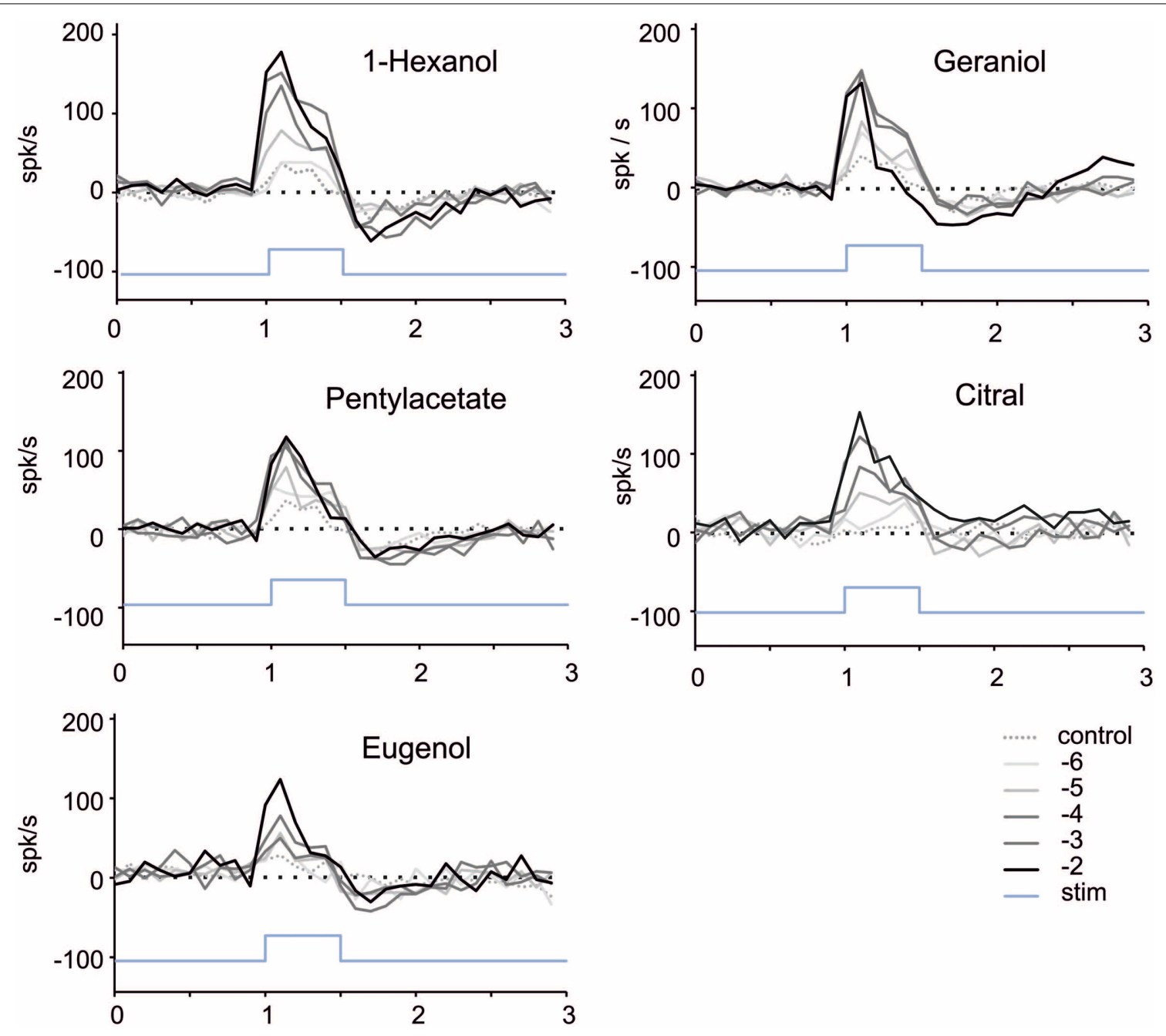

FIGURE 5 | Time course of the firing responses to stimulation. We computed the number of spikes occurring during consecutive $100 \mathrm{~ms}$ bins ( $n=8-12$ caterpillars, 1 stimulation per caterpillar for one dose of odorant). In order to reduce the dispersion of the curves due to inter-individual

et al., 2013). Even with such a reduced olfactory system, caterpillars have astonishing discrimination capabilities (Carroll et al., 2006; De Boer, 2006; Glendinning et al., 2009; Mooney et al., 2009; Piesik et al., 2009, 2013; Tanaka et al., 2009) which change according to experience or associative learning (Carlsson et al., 1999; Blackiston et al., 2008; Salloum et al., 2011).

In this work, we characterized the behavioral responses of S. littoralis larvae to selected natural odorants known either to be attractive or repellent in several species using a simple Petri dish assay. In $S$. littoralis, only a few studies identified relevant odorants for larvae (Carlsson et al., 1999; Salloum et al., 2011) and we chose 11 molecules which were commonly found in plants, and which had been documented to be either attractant or repellent. We show that caterpillars exhibit different responses depending on the odorant and its concentration. Among the 11 compounds tested, 1-hexanol, hexanal and cis-jasmone elicited a dose-dependent attraction $(P I>0.4)$ while camphene and eugenol were repellent $(P I<-0.4)$. E-(2)-hexen-(1)-ol and citral were attractive at lower doses while they were less efficient or even repellent at the highest concentration. This pattern is reminiscent of what has been observed in other Lepidoptera larvae, such as Yponomeuta cagnagellus and Y. padellus (Roessingh et al., 2007), Ostrinia nubilalis (Piesik et al., 2009), and Bombyx mori (Tanaka et al., 2009). In Drosophila, odorants are also attractive or repellent depending on the concentration (Acebes and Ferrus, 2001; Devaud, 2003).

The Petri dish assay, as opposed to more sophisticated behavioral observation setups, is a simple way to screen for behaviorally relevant odors in Lepidoptera larvae but it has limitations. This assay could be improved by using one larvae per Petri dish as opposed to groups of larvae, to prevent social interactions (Dussutour et al., 2008), which either reinforce attraction or expose larvae to aggressions. We often observed larvae engaging into aggressive behaviors in close vicinity to the food, presumably 


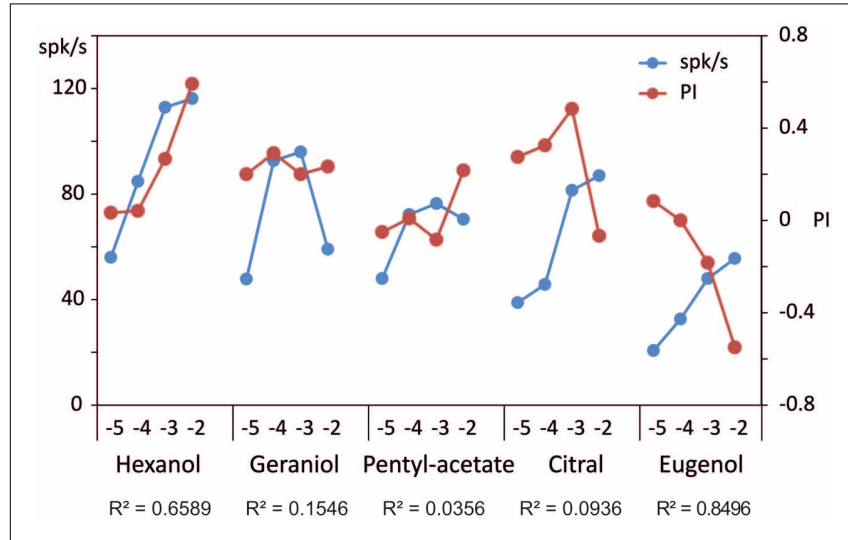

FIGURE 6 | Correlation between the electrophysiological responses and the behavioral responses. On this graph, we plotted the responses to each stimulus as measured on the behavior (PI: red dots) and by recording the spiking activity of B2 sensilla (spk/s: blue dots). A regression was computed between these 2 variables to evaluate if the spiking activity is a good predictor of the behavior (R2 displayed below the molecule name). The concentration of each stimulus is reported on the abscissa by the $\log _{10}$ value of the molar concentration.

a consequence of the starvation imposed on them prior to the experiment (Richardson et al., 2010). The assay should be limited in time since air saturation may occur rapidly, leading to possible larvae disorientation despite the use of fructose to retain insects near the pellet once they had found it. In addition, comparing the "olfactory" activity of the different chemicals tested should be made with caution, as the volatility of the odorants differs, especially since we deposited odorants as dilution in paraffin oil on the diet. Lastly, as larvae can learn to associate odorants with their food (Carlsson et al., 1999; Blackiston et al., 2008; Salloum et al., 2011), we need to keep in mind that natural components of the diet (Poitout and Bues, 1974) emit odorants (such as hexanol, hexanal and hexenol) which can influence the orientation behavior. We assumed here that this exposure did not significantly affect our observations but this hypothesis would need more rigorous testing.

After evaluating how caterpillars orient toward odorants, we recorded responses from olfactory neurons on the antenna of these larvae in the hope to find either neurons specialized to any of these odorants or physiological correlates with their attractiveness or repellency. We focused on sensillum B2 of the antenna because in our hands, this sensillum was more accessible to recordings than the others. B2 neurons responded to all stimuli tested in this study by an increase in the spiking activity. In the absence of any olfactory stimulus, the baseline activity of these neurons was high (about 100 spikes/s) which is in stark contrast with the low basal activity recorded in pheromone sensilla of the adults (about 5-20 spikes/s) (Binyameen et al., 2012). This activity was usually maintained during the whole recording session. It could be genuine, i.e., related to the specific olfactory receptors expressed in the larval olfactory receptor neurons (Hallem et al., 2004). This high baseline activity could make room for encoding odorants both with excitation and with inhibition. None of the odorants reduced the global spiking activity nor did they induce a prolonged after-response modification of the spiking activity. Thus, from the time-course of the electrophysiological responses collected in sensillum B2, we cannot identify if the compounds tested are attractive or repellent for the larvae. However, we have found a good correlation between our electrophysiological observations for hexanol and eugenol (Figure 6), for which a higher spiking activity correlates well with either attraction (hexanol) or repellency (eugenol). For the other chemicals tested (geraniol, pentyl-acetate, and citral), the relation is not clear. These observations suggest that sensillum B2 host neuron(s) responding to hexanol and eugenol which activity is directly correlated to the orientation behavior, while other neurons which fire in response to pentyl acetate, geraniol and citral are not decisive in inducing an orientation behavior. Electrophysiology is thus not a good predictor of the behavior.

The responses observed at the periphery are consistent with the hypothesis that olfactory receptor neurons in the larvae are generalist, at least in B2 sensilla. In adults of S. littoralis, while olfactory neurons tuned to pheromone components are highly specific and sensitive (Ljungberg et al., 1993), the olfactory neurons specificity to plant stimuli ranged from highly specific to broadly tuned (Anderson et al., 1995, 1996; Jönsson and Anderson, 1999; Binyameen et al., 2012). In the larvae, the reaction spectra of the olfactory receptor neurons of sensillum B2 are overlapping but not identical as the dose-response curves of the responses exhibit different shapes. These observations concur with our former report, where we demonstrated that neurons in sensillum B2 respond to the sexual pheromone (Poivet et al., 2012). This indicates that olfactory receptor neurons of S. littoralis caterpillars respond to different odorants without being specialized to specific molecules.

Similar observations were reported by other authors who examined the olfactory responses of different species of caterpillars, such as Manduca sexta (Dethier and Schoonhoven, 1969) and Malacosoma americanum (Dethier, 1980b). More recently, Roessingh et al. (2007) examined the responses of olfactory receptors of the maxillary palps of Yponomeuta cagnagellus. They found cells that responded to structurally different compounds such as (Z)-3-hexenol and benzaldehyde, but also cells that responded to only one of these two compounds. Generalist cells could express olfactory receptors which are loosely tuned to several odorants. Our results are also in concordance with the observations of Itagaki and Hildebrand (1990) who studied the olfactory interneurons in the brain of Manduca sexta caterpillars. They did not find any neuron that responded to only one odor; all cells that responded to one of the olfactory stimuli also responded to some or all of the others. They suggest that caterpillar assesses the quality of different odors by an 'across-fiber' firing pattern of the olfactory interneurons in its central nervous system.

Even if S. littoralis larvae are equipped with only a few "generalists" receptors, they possess the potentiality for generating distinct behavioral responses, which are elaborated at the level of the central nervous system that analyses and interpret the receptors activity pattern. The encoding capabilities of their limited olfactory system are therefore striking. It suggests an across fiber coding by broadly tuned neurons and makes it unlikely that each cell expresses only one receptor. That larvae are able of such 
fine discriminations strongly suggests that odorants play a strong role in their biology. Actually, although the "mothers know best" principle is generally true (Garcia-Robledo and Horvitz, 2012), implying that the host choices are determined by adults, more experimental situations show that larvae need to orient and make choices based on odors (Piesik et al., 2009, 2013), especially in larvae like $S$. littoralis which have been described to leave their host plant during day time to hide on the ground (Hosny et al., 1982) and to rely on a wide range of odorants to orient, including pheromones and past experience (Salloum et al., 2011; Poivet et al., 2012).

\section{ACKNOWLEDGMENTS}

This work has been supported by a postdoctoral grant from INRA to Kacem Rharrabe, by recurrent funding from the Ministry of Agriculture to Frédéric Marion-Poll and by ANR- 09-BLAN0239-01 funding.

\section{REFERENCES}

Acebes, A., and Ferrus, A. (2001). Increasing the number of synapses modifies olfactory perception in Drosophila. J. Neurosci. 21, 6264-6273.

Anderson, P., Hansson, B. S., and Lofqvist, J. (1995). Plant-odor-specific receptor neurons on the antennae of female and male Spodoptera littoralis. Physiol. Entomol. 20, 189-198. doi: 10.1111/j.1365-3032.1995.tb00001.x

Anderson, P., Larsson, M., Lofqvist, J., and Hansson, B. S. (1996). Plant odour receptor neurones on the antennae of the two moths Spodoptera littoralis and Agrotis segetum. Entomol. Exp. Appl. 80, 32-34. doi: 10.1111/j.15707458.1996.tb00879.x

Becher, P. G., and Guerin, P. M. (2009). Oriented responses of grapevine moth larvae Lobesia botrana to volatiles from host plants and an artificial diet on a locomotion compensator. J. Insect Physiol. 55, 384-393. doi: 10.1016/j.jinsphys.2009.01.006

Bernays, E., and Graham, M. (1988). On the evolution of host specificity in phytophagous arthropods. Ecology 69, 886-892. doi: 10.2307/1941237

Binyameen, M., Anderson, P., Ignell, R., Seada, M. A., Hansson, B. S., and Schlyter, F. (2012). Spatial organization of antennal olfactory sensory neurons in the female Spodoptera littoralis moth: differences in sensitivity and temporal characteristics. Chem. Senses 37, 613-629. doi: 10.1093/chemse/bjs043

Blackiston, D. J., Silva Casey, E., and Weiss, M. R. (2008). Retention of memory through metamorphosis: can a moth remember what it learned as a caterpillar? PLoS ONE 3:e1736. doi: 10.1371/journal.pone.0001736

Carlsson, M. A., Anderson, P., Hartlieb, E., and Hansson, B. S. (1999). Experience-dependent modification of orientational response to olfactory cues in larvae of Spodoptera littoralis. J. Chem. Ecol. 25, 2445-2454. doi: 10.1023/A:1020865922827

Carroll, M., Schmelz, E., and Teal, P. (2008). The attraction of Spodoptera frugiperda neonates to cowpea seedlings is mediated by volatiles induced by conspecific herbivory and the elicitor inceptin. J. Chem. Ecol. 34, 291-300. doi: 10.1007/s10886-007-9414-y

Carroll, M. J., and Berenbaum, M. R. (2002). Behavioral responses of the parsnip webworm to host plant volatiles. J. Chem. Ecol. 28, 2191-2201. doi: 10.1023/A:1021093114663

Carroll, M. J., Schmelz, E. A., Meagher, R. L., and Teal, P. E. A. (2006). Attraction of Spodoptera frugiperda larvae to volatiles from herbivore-damaged maize seedlings. J. Chem. Ecol. 32, 1911-1924. doi: 10.1007/s10886-006-9117-9

Castrejon, F., Virgen, A., and Rojas, J. C. (2006). Influence of chemical cues from host plants on the behavior of neonate Estigmene acrea larvae (Lepidoptera: Arctiidae). Environ. Entomol. 35, 700-707. doi: 10.1603/0046-225X-35.3.700

De Boer, G. (2006). The role of the antennae and maxillary palps in mediating food preference by larvae of the tobacco hornworm, Manduca sexta. Entomol. Exp. Appl. 119, 29-38. doi: 10.1111/j.1570-7458.2006.00397.x

Del Campo, M. L., Palmer, S., and Caillaud, M. (2011). Characterization of a new odorant binding protein gene in gustatory organs of Manduca sexta larvae (Lepidoptera: Sphingidae). Ann. Entomol. Soc. Am. 104, 319-325. doi: 10.1603/an10091
Dethier, V. G. (1980a). Food-aversion learning in two polyphagous caterpillars, Diacrisia virginica and Estigmene congrua. Physiol. Entomol. 5, 321-325. doi: 10.1111/j.1365-3032.1980.tb00242.x

Dethier, V. G. (1980b). Responses of some olfactory receptors of the eastern tent caterpillar (Malacosoma americanum) to leaves. J. Chem. Ecol. 6, 213-220. doi: 10.1007/BF00987540

Dethier, V. G., and Schoonhoven, L. M. (1969). Olfactory coding by Lepidopterous larvae. Entomol. Exp. Appl. 12, 535-543. doi: 10.1111/j.15707458.1969.tb02551.x

Devaud, J. M. (2003). Experimental studies of adult Drosophila chemosensory behaviour. Behav. Processes 64, 177-196. doi: 10.1016/S0376-6357(03)00134-7

Dussutour, A., Nicolis, S. C., Despland, E., and Simpson, S. J. (2008). Individual differences influence collective behaviour in social caterpillars. Anim. Behav. 76, 5-16. doi: 10.1016/j.anbehav.2007.12.009

Garcia-Robledo, C., and Horvitz, C. C. (2012). Parent-offspring conflicts, "optimal bad motherhood" and the "mother knows best" principles in insect herbivores colonizing novel host plants. Ecol. Evol. 2, 1446-1457. doi: 10.1002/ ece3.267

Glendinning, J. I., Foley, C., Loncar, I., and Rai, M. (2009). Induced preference for host plant chemicals in the tobacco hornworm: contribution of olfaction and taste. J. Comp. Physiol. A Neuroethol. Sens. Neural Behav. Physiol. 195, 591-601. doi: 10.1007/s00359-009-0434-7

Grimes, L. R., and Neunzig, H. H. (1986). Morphological survey of the maxillae in last stage larvae of the suborder ditrysia (Lepidoptera): Palpi. Ann. Entomol. Soc. Am. 79, 491-509.

Hallem, E. A., Ho, M. G., and Carlson, J. R. (2004). The molecular basis of odor coding in the Drosophila antenna. Cell 117, 965-979. doi: 10.1016/j.cell.2004.05.012

Hansson, B. S., and Stensmyr, M. C. (2011). Evolution of insect olfaction. Neuron 72, 698-711. doi: 10.1016/j.neuron.2011.11.003

Hosny, M. M., Iss-Hak, R. R., and Foda, M. E. (1982). Daily movement and Time of Activity of the Egyptian Cotton Leafworm Larvae, Spodoptera Littoralis (Boisd.) on Cotton Plants. Cairo: Research Bulletin, Faculty of Agriculture, Ain Shams University, $4[+7]$.

Huang, X. P., and Mack, T. P. (2002). Collection and determination of lesser cornstalk borer (Lepidoptera: Pyralidae) larval attractant from peanut plants. Environ. Entomol. 31, 15-21. doi: 10.1603/0046-225X-31.1.15

Itagaki, H., and Hildebrand, J. G. (1990). Olfactory interneurons in the brain of the larval sphinx moth Manduca sexta. J. Comp. Physiol. A. 167, 309-320. doi: 10.1007/BF00192566

Jacquin-Joly, E., Legeai, F., Montagne, N., Monsempes, C., Francois, M.-C., Poulain, J., et al. (2012). Candidate chemosensory genes in female antennae of the noctuid moth Spodoptera littoralis. Int. J. Biol. Sci. 8, 1036-1050. doi: 10.7150/ijbs.4469

Jallow, M. F., and Zalucki, M. P. (2003). Relationship between oviposition preference and offspring performance in Australian Helicoverpa armigera (Hübner) (Lepidoptera: Noctuidae). Aust. J. Entomol. 42, 343-348. doi: 10.1046/j.14406055.2003.00365.x

Jönsson, M., and Anderson, P. (1999). Electrophysiological response to herbivoreinduced host plant volatiles in the moth Spodoptera littoralis. Physiol. Entomol. 24, 377-385. doi: 10.1046/j.1365-3032.1999.00154.x

Laue, M. (2000). Immunolocalization of general odorant-binding protein in antennal sensilla of moth caterpillars. Arthropod Struct. Dev. 29, 57-73. doi: 10.1016/S1467-8039(00)00013-X

Legeai, F., Malpel, S., Montagne, N., Monsempes, C., Cousserans, F., Merlin, C., et al. (2011). An Expressed Sequence Tag collection from the male antennae of the noctuid moth Spodoptera littoralis: a resource for olfactory and pheromone detection research. BMC Genomics 12:86. doi: 10.1186/1471-2164$12-86$

Liu, Y., Gu, S., Zhang, Y., Guo, Y., and Wang, G. (2012). Candidate Olfaction Genes Identified within the Helicoverpa armigera Antennal Transcriptome. PLoS ONE 7:e48260. doi: 10.1371/journal.pone.0048260

Ljungberg, H., Anderson, P., and Hansson, B. S. (1993). Physiology and morphology of pheromone-specific sensilla on the antennae of male and female Spodoptera littoralis (Lepidoptera: Noctuidae). J. Insect Physiol. 39, 253-260. doi: 10.1016/0022-1910(93)90096-a

Louis, M., Huber, T., Benton, R., Sakmar, T. P., and Vosshall, L. B. (2008). Bilateral olfactory sensory input enhances chemotaxis behavior. Nat. Neurosci. 11, 187-199. doi: 10.1038/nn2031 
Malpel, S., Merlin, C., Francois, M. C., and Jacquin-Joly, E. (2008). Molecular identification and characterization of two new Lepidoptera chemoreceptors belonging to the Drosophila melanogaster OR83b family. Insect Mol. Biol. 17, 587-596. doi: 10.1111/j.1365-2583.2008.00830.x

Marion-Poll, F. (1996). Display and analysis of electrophysiological data under MS-Windows. Entomol. Exp. Appl. 80, 116-119. doi: 10.1111/j.1570-7458.1996. tb00900.x

Montagne, N., Chertemps, T., Brigaud, I., Francois, A., Francois, M. C., De Fouchier, A., et al. (2012). Functional characterization of a sex pheromone receptor in the pest moth Spodoptera littoralis by heterologous expression in Drosophila. Eur. J. Neurosci. 36, 2588-2596. doi: 10.1111/j.1460-9568.2012. 08183.x

Mooney, A. C., Robertson, H. M., and Wanner, K. W. (2009). Neonate silkworm (Bombyx mori) larvae are attracted to mulberry (Morus alba) leaves with conspecific feeding damage. J. Chem. Ecol. 35, 552-559. doi: 10.1007/s10886-0099639-z

Morita, H., and Yamashita, S. (1961). Receptor potentials recorded from sensilla basiconica on the antenna of the silkworm larvae, Bombyx mori. J. Exp. Biol. 38, 851-861.

Piesik, D., Rochat, D., Delaney, K. J., and Marion-Poll, F. (2013). Orientation of European corn borer first instar larvae to synthetic green leaf volatiles. J. Appl. Entomol. 137, 234-240. doi: 10.1111/j.1439-0418.2012.01719.x

Piesik, D., Rochat, D., Van Der Pers, J., and Marion-Poll, F. (2009). Pulsed odors from maize or spinach elicit orientation in European corn borer neonate larvae. J. Chem. Ecol. 35, 1032-1042. doi: 10.1007/s10886-009-9676-7

Poitout, S., and Bues, R. (1974). Elevage de chenilles de vingt-huit espèces de lépidopteres Noctuidae et de deux especes d'Arctiidae sur milieu artificiel simple. Particularités de l'élevage selon les espèces. Ann. Zool. Ecol. Anim. 6, 431-441.

Poivet, E., Gallot, A., Montagne, N., Glaser, N., Legeai, F., and Jacquin-Joly, E. (2013). A Comparison of the olfactory gene repertoires of adults and larvae in the noctuid moth Spodoptera littoralis. PLoS ONE 8:e60263. doi: 10.1371/journal.pone. 0060263

Poivet, E., Rharrabe, K., Monsempes, C., Glaser, N., Rochat, D., Renou, M., et al. (2012). The use of the sex pheromone as an evolutionary solution to food source selection in caterpillars. Nat. Commun. 3, 1047. doi: 10.1038/ncomms2050

Pottier, M. A., Bozzolan, F., Chertemps, T., Jacquin-Joly, E., Lalouette, L., Siaussat, D., et al. (2012). Cytochrome P450s and cytochrome P450 reductase in the olfactory organ of the cotton leafworm Spodoptera littoralis. Insect Mol. Biol. 21, 568-580. doi: 10.1111/j.1365-2583.2012.01160.x

Richardson, M. L., Mitchell, R. F., Reagel, P. F., and Hanks, L. M. (2010). Causes and Consequences of Cannibalism in Noncarnivorous Insects. Annu. Rev. Entomol. 55, 39-53. doi: 10.1146/annurev-ento-112408-085314

Roessingh, P., Xu, S., and Menken, S. B. (2007). Olfactory receptors on the maxillary palps of small ermine moth larvae: evolutionary history of benzaldehyde sensitivity. J. Comp. Physiol. A. 193, 635-647. doi: 10.1007/s00359-007-0218-x
Rojas, J. C., and Wyatt, T. D. (1999). The role of pre- and post-imaginal experience in the host-finding and oviposition behaviour of the cabbage moth. Physiol. Entomol. 24, 83-89. doi: 10.1046/j.1365-3032.1999. 00117.x

Salloum, A., Colson, V., and Marion-Poll, F. (2011). Appetitive and aversive learning in Spodoptera littoralis larvae. Chem. Senses 36, 725-731. doi: 10.1093/chemse/bjr041

Saxena, K. N., and Schoonhoven, L. M. (1982). Induction of orientational and feeding preferences in Manduca sexta larvae for different food sources. Entomol. Exp. Appl. 32, 173-180. doi: 10.1111/j.1570-7458.1982.tb03199.x

Schoonhoven, L. M., and Dethier, V. G. (1966). Sensory aspects of host-plant discrimination by lepidopterous larvae. Arch. Néerlandaises Zool. 16, 497-530. doi: 10.1163/036551666X00057

Singh, A. K., and Mullick, S. (2002). Leaf volatiles as attractants for neonate Helicoverpa armigera Hbn. (Lep., Noctuidae) larvae. J. Appl. Entomol. 126, 14-19. doi: 10.1046/j.1439-0418.2002.00600.x

Tanaka, K., Uda, Y., Ono, Y., Nakagawa, T., Suwa, M., Yamaoka, R., et al. (2009). Highly selective tuning of a silkworm olfactory receptor to a key mulberry leaf volatile. Curr. Biol. 19, 881-890. doi: 10.1016/j.cub.2009.04.035

Thompson, J. N. (1988). Evolutionary genetics of oviposition preference in swallowtail butterflies. Evolution 42, 1223-1234. doi: 10.2307/2409006

Vogt, R. G., Rogers, M. E., Franco, M. D., and Sun, M. (2002). A comparative study of odorant binding protein genes: differential expression of the PBP1-GOBP2 gene cluster in Manduca sexta (Lepidoptera) and the organization of OBP genes in Drosophila melanogaster (Diptera). J. Exp. Biol. 205, 719-744.

Conflict of Interest Statement: The authors declare that the research was conducted in the absence of any commercial or financial relationships that could be construed as a potential conflict of interest.

Received: 02 January 2014; paper pending published: 21 January 2014; accepted: 09 March 2014; published online: 24 March 2014.

Citation: Rharrabe K, Jacquin-Joly E and Marion-Poll F (2014) Electrophysiological and behavioral responses of Spodoptera littoralis caterpillars to attractive and repellent plant volatiles. Front. Ecol. Evol. 2:5. doi: 10.3389/fevo.2014.00005

This article was submitted to Chemical Ecology, a section of the journal Frontiers in Ecology and Evolution.

Copyright (C) 2014 Rharrabe, Jacquin-Joly and Marion-Poll. This is an openaccess article distributed under the terms of the Creative Commons Attribution License (CC BY). The use, distribution or reproduction in other forums is permitted, provided the original author(s) or licensor are credited and that the original publication in this journal is cited, in accordance with accepted academic practice. No use, distribution or reproduction is permitted which does not comply with these terms. 